\title{
In Vitro Release Evaluation of Gastroretentive Amoxicillin Floating Tablets Employing a Specific Design of the Flow-Through Cell
}

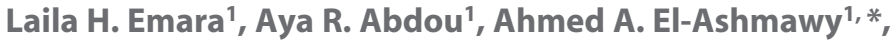 \\ Rania M. Badr ${ }^{1}$, Nesrin F. Taha ${ }^{1}$, and Nadia M. Mursi ${ }^{2}$ \\ 'Industrial Pharmacy Laboratory, Medical and Pharmaceutical Chemistry Department, \\ Division of Pharmaceutical Industries, National Research Centre, El-Tahrir Street, Dokki, Giza 12622, Egypt \\ ${ }^{2}$ Department of Pharmaceutics, Faculty of Pharmacy, Cairo University, Egypt
}

\begin{abstract}
Floating amoxicillin trihydrate (AmoxT) tablets, used for eradication of Helicobacter pylori (H. pylori), were prepared according to a gas-generating technique to extend the drug residence time in the stomach. The drug release rate from the floating tablets in acidic dissolution medium, in which AmoxT is known to be unstable, was studied using two dissolution techniques: openloop system of the flow-through cell (FTC) and the beaker method. Analysis of AmoxT in the dissolution medium was carried out by UV spectrophotometric and HPLC methods. The comparison indicates that the open-loop system of the FTC, which is based on non-cumulative (fresh) dissolution samples, is the preferred dissolution technique, and in this case, the drug could be analyzed by UV spectrophotometric and HPLC methods. However, in the case of a large number of QC samples, UV spectrophotometry is preferred to the HPLC method, which requires relatively longer time for analysis thereby increasing drug degradation. On the other hand, in the case of the beaker method, which is based on cumulative dissolution samples, the drug must be analyzed by HPLC. Generally, the beaker method is not recommended due to the problems associated with the accumulation of AmoxT degradation product in the dissolution medium. This study describes a simple dissolution method capable of discriminating between different AmoxT gastroretentive formulations without any additional experimental or calculational steps.
\end{abstract}

\section{INTRODUCTION}

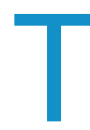

he lifetime risk for developing a peptic ulcer is approximately $10 \%$ of the general population (1, 2). H.pylori is one of the major causative agents of peptic ulcer (1). Although many antibacterial agents have a very low minimum inhibitory concentration (MIC) against H.pylori in vitro (3), no single agent is effective in the eradication of the infection in vivo when administered alone (4). In addition, single antibiotic therapy is strongly discouraged to prevent the development of resistant strains (5). There could be one or several reasons for the failure of single-antibiotic therapy against H.pylori. Firstly, the organism resides in the mucus gel close to the acidic environment of the gastric fluid. Many antibacterial agents, such as penicillin and erythromycin, degrade rapidly in acidic medium. Secondly, the drug must diffuse into the mucus layer to furnish concentrations sufficient for antibacterial activity. Lastly, the contact time of antibacterial drugs with the organism needs to be sufficiently long for successful eradication of H.pylori from the gastric mucosa (6), which can be achieved through a gastroretentive drug delivery system (GRDDS).

Gastric residence time of an oral dosage form is affected by several factors. To pass through the pyloric valve into the small intestine, the particle size should be in the range of $1-2 \mathrm{~mm}(7,8)$. The rate of gastric emptying depends

${ }^{*}$ Corresponding author. mainly on viscosity, volume, and caloric content of meals. The nutritive density of meals helps to determine gastric emptying time. It does not make any difference whether the meal has high protein, fat, or carbohydrate content as long as the caloric content is the same. However, an increase in acidity and caloric value slows down gastric emptying time. Biological factors such as age, body mass index (BMI), gender, posture, and diseased states (diabetes, Crohn's disease) influence gastric emptying. In the case of elderly people, gastric emptying is slowed down. Generally, females have slower gastric emptying rates than males. Stress increases gastric emptying rates while depression slows it down $(7,9,10)$.

Different drug delivery methods can be used for gastric retention such as floating (11), mucoadhesive, superporous hydrogel, expandable, magnetic, and high-density systems (12). GRDDS is superior for (1) drugs that are locally active in the stomach (e.g., misroprostol, antacids); (2) drugs that have narrow absorption windows in the gastrointestinal tract (GIT) (e.g., L-DOPA, para aminobenzoic acid, furosemide, riboflavin); (3) drugs that are unstable in the intestinal or colonic environment (e.g., captopril, ranitidine $\mathrm{HCl}$, metronidazole); (4) drugs that disturb normal colonic microbes (e.g., antibiotics against $H$. pylori); and (5) drugs that exhibit low solubility at high $\mathrm{pH}$ values (e.g., diazepam, chlordiazepoxide, verapamil $\mathrm{HCl}$ ) (13).

In practice, drugs that are less soluble in a high $\mathrm{pH}$ environment require more retention time in the stomach to improve 
solubility and bioavailability and to reduce drug waste. Prolonging gastric retention also has applications for local drug delivery to the stomach and proximal small intestine (14).

Amoxicillin is one of the main antibiotics given as part of treatment regimens to eradicate $H$. pylori infection in patients with peptic ulcer disease. For the eradication of $H$. pylori, amoxicillin is given with either metronidazole or clarithromycin and a proton-pump inhibitor. Ranitidine bismuth citrate may replace the proton-pump inhibitor. The usual doses of amoxicillin are 0.75 or $1.00 \mathrm{~g}$ twice daily or $500 \mathrm{mg}$ three times daily (15). For gastric ulcer patients, amoxicillin is ineffective even at high doses, apparently due to limited contact time with the target site when administered in a conventional oral dosage form (16). The failure of amoxicillin has been proposed to be an outcome of subtherapeutic bactericidal concentrations available at the site and instability of amoxicillin following oral administration $(17,18)$. H. pylori live deep within the gastric mucus layer, and prolonged local application of drug is needed for its sufficient diffusion to the bacteria. A logical way to improve the effectiveness of therapy is to develop a drug delivery system that can reside in the stomach for a longer duration and release drug as long as possible in the ecological niche of the bacterium (12), and GRDDS is an ultimate solution for this (19).

An oral sustained-release formulation fits the therapeutic goals of antimicrobial therapy with amoxicillin (a representative $\beta$-lactam antibiotic) by assuring effective drug concentrations for a prolonged period (20). The rationale leading to this conclusion is based on the following points:

\section{Pharmacodynamic rationale:}

(1) Elevation of $\beta$-lactam concentration demonstrates increased bacterial killing only until a finite point, which tends to be about four times the minimal inhibitory concentration (MIC). Further elevation is not associated with increased bactericidal potency (21).

(2) Elevation of serum drug concentration will not contribute much in cases where the pathogen is located intracellularly.

(3) A direct correlation exists between the time the $\beta$-lactam antibiotic concentrations are maintained above the therapeutic concentration and the clinical outcomes $(22,23)$.

(4) There is no correlation between the area under the concentration versus time curve (AUC) and the magnitude of effect in vivo.

(5) Kinetics of bactericidal effect is slow and requires prolonged maintenance of effective concentrations of the drug in order to achieve onset of effect.

(6) Continuous administration may result in lower toxicity than the administration of large and potentially toxic bolus doses (20).

\section{Pharmacokinetic rationale:}

(1) $\beta$-Lactam antibiotics exhibit short biological half-life values (22-24).
(2) A realistic link can be drawn between the in vivo serum concentration and the in vitro measured parameter (MIC) (20).

In addition, Weitschies et al. (25) reported that amoxicillin is not suitable for extended-release delivery unless it is given under conditions that delay gastric emptying because of the absorption window in the upper Gl tract (25).

Several dissolution methods have been used to evaluate GRDDS, among which the USP Apparatus 2 (paddle) is the most commonly used. However, this may be associated with a number of difficulties such as adherence of the tested product to the paddle shaft or sample withdrawal aid (pipette), incomplete exposure to the dissolution medium, and failure to predict in vivo performance (26). To overcome such problems, some researchers have alternatively used certain modifications to the paddle method $(27,28)$, modified the dissolution apparatus $(26,29,30)$, or used the FTC (USP Apparatus 4) (31).

In this regard, Ozdemir et al. (31) reported that the FTC is an ideal method for testing floating dosage forms, where his results showed a significant correlation between the in vitro and in vivo data for furosemide double-layer floating tablet. On the other hand, Tokumura and Machida (32) studied a dissolution method in acidic solution at $\mathrm{pH}$ 1.2 for a sustained-release floating tablet dosage form of amoxicillin using a conventional paddle apparatus. The determination of amoxicillin was simultaneously performed for the same sample solutions by two different methods (UV absorption and HPLC) (32). The study concluded that the UV spectrophotometric method should not be used for the determination of amoxicillin under the described dissolution conditions and that this could be solved by an HPLC method (32). Umamaheshwari et al. (33) studied the stability of amoxicillin in simulated gastric fluid ( $\mathrm{pH} 1.2)$. They reported that amoxicillin degradation was quick and displayed strict first-order kinetics. After $16 \mathrm{~h}$, approximately $50 \%$ of the starting amoxicillin amount was degraded.

The FTC was developed to address some deficiencies perceived in other compendial techniques and offers a viable option for carrying out dissolution of various dosage forms such as tablets, powders, suppositories, hard gelatin capsules, implants, semisolids, and drug-eluting stents (34-36). This method has distinct advantages over the USP paddle and basket methods, especially for drugs with poor solubility and wettability $(37,38)$. Powders with very low solubility and wettability present unique problems that necessitate optimized methods of sample loading into the flow-through dissolution cell to achieve acceptable results. The flow-through dissolution apparatus is specially designed to have a small holdup volume compared with other USP apparatus, which helps to minimize spreading of drug particles to undefined sites of the apparatus (39).

Moreover, FTC is helpful in testing robustness of the formulation with respect to the variations in the intralumenal environment, maintaining sink conditions for the poorly solu- 
ble drugs $(31,34,40)$, and non-tedious method to change $\mathrm{pH}$ of the dissolution medium $(34,41)$. In addition, FTC systems offer other distinct advantages including (1) a built-in filtration system, (2) use as either an open or closed system, (3) a high degree of automation, (4) ideal hydrodynamic conditions for mild agitation, homogeneity, and definable flow (37, 38), and (5) release from dosage forms over extended periods can be studied, as FTC eliminates the evaporation issue that can be observed with other apparatus (42).

The FTC offers a controlled hydrodynamic environment pumped by either a laminar or turbulent flow mode, in which intralumenal hydrodynamics are more efficiently simulated than with other in vitro setups. The hydrodynamics inside the cell are not affected by media change and sampling, as can occur in traditional closed systems (i.e., rotating paddle apparatus, rotating basket apparatus). Also, the need for further stirring is eliminated due to the pulsating pattern of the pump. USP, Ph. Eur., and $J P$ have harmonized on the possibility that the pump is pulseless (42). Therefore, FTC assures that the tests are carried out under well-controlled conditions of agitation and uninterrupted sampling that are capable of discriminating between products and detecting any formulation changes that might affect drug bioavailability (42).

The objective of this study was to develop and optimize an in vitro dissolution method for evaluation of AmoxT GRDDS to solve the problems of unreliable release rate data due to the interference of the AmoxT degradation product and to suit floating formulations as well. A model gas-generating floating formula was prepared (43) and evaluated by two different dissolution techniques, an open-loop system of the FTC and a beaker method. In addition, due to the instability of AmoxT in acidic medium, the suitability of the assay methods, UV spectrophotometry and HPLC, was compared.

\section{MATERIALS AND METHODS Materials}

Amoxicillin trihydrate powder (AmoxT), (6R)-6-[ $\alpha-D-(4-$ hydroxyphenyl)glycylamino] penicillanic acid trihydrate (15), was received as a gift from the Egyptian International Pharmaceutical Industries CO (EIPICO). Reagent grade chemicals were used unless otherwise indicated. Poly(ethylene oxide) (PEO) of molecular weights 900,000 and 8,000,000 (Aldrich, Germany), calcium carbonate $\left(\mathrm{CaCO}_{3}\right)(\mathrm{BDH}$ Laboratory Supplies, England), sodium bicarbonate $\left(\mathrm{NaHCO}_{3}\right)$ (Kahira Pharm., Egypt), and lactose monohydrate (BDH Laboratory Supplies, England) were used in tablet preparation. Hydrochloric acid $(32.5 \%$ w/w) (ADWIA, Egypt) was used to prepare the dissolution medium. Milli-Q purified water (Millipore Corp., Billerica, MA, USA) was used to prepare both dissolution media and HPLC mobile phase. Potassium dihydrogen orthophosphate (Laboratory Rasayan, India), ortho-phosphoric acid 85\% (Extra-pure, Merck, Germany), triethylamine (for synthesis, Merck, Germany), and methanol (HPLC grade,
Prolabo, France) were used to prepare the HPLC mobile phase.

\section{Methods}

Preparation of AmoxT Sustained-Release Effervescent Floating Tablets

AmoxT ( $375 \mathrm{mg} /$ tablet) was prepared in swellable, effervescent floating tablets according to a previous study (43). The formula consisted of a blend of poly(ethylene oxide) (1:1, MW of 900,000 and $8,000,000), \mathrm{CaCO}_{3}, \mathrm{NaHCO}_{3}$, and lactose with 240, 40, 20, and $25 \mathrm{mg} /$ tablet. Tablets were prepared by direct compression at a 1.5-ton compression force (Single Punch Press, Stokes-Merrill Model 511-7-A, USA). Round, flat-surface tablets with an average weight of $700 \mathrm{mg}$ were produced.

\section{Determination of Floating Lag Time and Floating Duration of AmoxT Tablets}

The time required for the tablets to emerge on the dissolution medium surface (floating lag time) and the time the tablets remained floating on the dissolution medium surface (floating duration) were inspected visually in a 1-L jacketed beaker connected to Julabo circulator (F10-VC, Germany) filled with $400 \mathrm{~mL} 0.1 \mathrm{~N} \mathrm{HCl}, \mathrm{pH} 1.2(44)$, at $37 \pm 0.5^{\circ} \mathrm{C}$ (45). The results were registered as an average of three repetitions.

Development and Validation of a Stability Indicating HPLC/ UV Method for the In Vitro Determination of AmoxT

The analysis of AmoxT and its degradation product in acidic medium was a modification of a previously reported method (46) as follows. An HPLC (Waters 600E Multi Solvent Delivery System Controller equipped with Rheodyne injector, P/N 7725i, and Waters 2487 Dual Absorbance Detector set at $230 \mathrm{~nm}$ coupled with a Millennium 32 computer program) was connected to reversed phase C18 column (Thermo Hypersil: $250 \times 4.6 \mathrm{~mm}, 5 \mu \mathrm{m}$, BDS). The mobile phase was $0.05 \mathrm{M}$ phosphate buffer containing $0.1 \% \mathrm{v} / \mathrm{v}$ triethanolamine $(\mathrm{pH} 3) /$ methanol (90:10), pumped at a flow rate of $1.2 \mathrm{~mL} / \mathrm{min}$.

\section{Design of a Specific In Vitro Dissolution Study for AmoxT Floating Tablets}

An in vitro release study of the prepared floating AmoxT tablets in acidic medium ( $\mathrm{pH}$ 1.2) was done using both the open-loop system of the FTC apparatus (USP Apparatus 4, Sotax, Switzerland) and the beaker method (simulating the USP paddle method). Each test was conducted in triplicate.

For the open-loop system of the FTC, a laminar flow (free tablet position with the glass beads filling the entry cone) with a rate of $8 \pm 0.2 \mathrm{~mL} / \mathrm{min}$ was used. Each tablet was placed in the large dissolution cell (22.6- $\mathrm{mm}$ diameter). This cell design was developed especially for floating dosage forms as it allows for undisturbed floating of the tablet (Figure 1). The dissolution medium was filtered, degassed $0.1 \mathrm{~N} \mathrm{HCl}(\mathrm{pH} \mathrm{1.2)}$ maintained at $37.0 \pm 0.5^{\circ} \mathrm{C}$. 
For the beaker method, 1-L jacketed beakers connected to a circulator apparatus (Julabo circulators F10-VC, Germany) were used. The dissolution medium was $900 \mathrm{~mL}$ $0.1 \mathrm{~N} \mathrm{HCl}(\mathrm{pH} 1.2)$ maintained at $37.0 \pm 0.5^{\circ} \mathrm{C}$. A constant stirring rate was maintained in each beaker using a magnetic stirrer with a magnet kept underneath a stainless steel mesh (fixed height of $1.5 \mathrm{~cm}$ ) placed on the bottom of each beaker (Figure 2).

Sample fractions obtained from both dissolution tests were collected at specified intervals for up to $6 \mathrm{~h}$. To measure the amount of AmoxT released, each sample fraction was divided into two portions, one of which was analyzed by the UV spectrophotometric method (UV-vis spectrophotometer, Beckman, DU-650, USA) at $272 \mathrm{~nm}$ and the other by the HPLC method. AmoxT concentration was calculated using the constructed linear calibration curve.

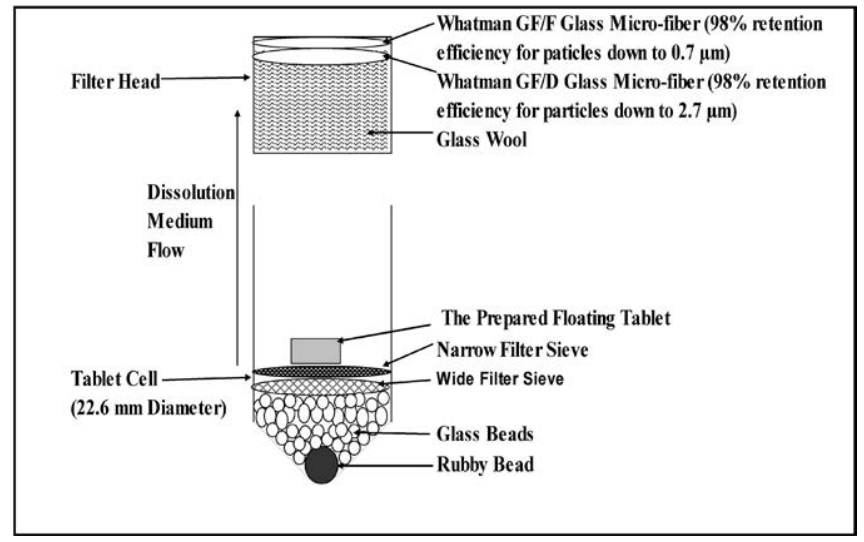

Figure 1. Schematic diagram of the FTC cell.

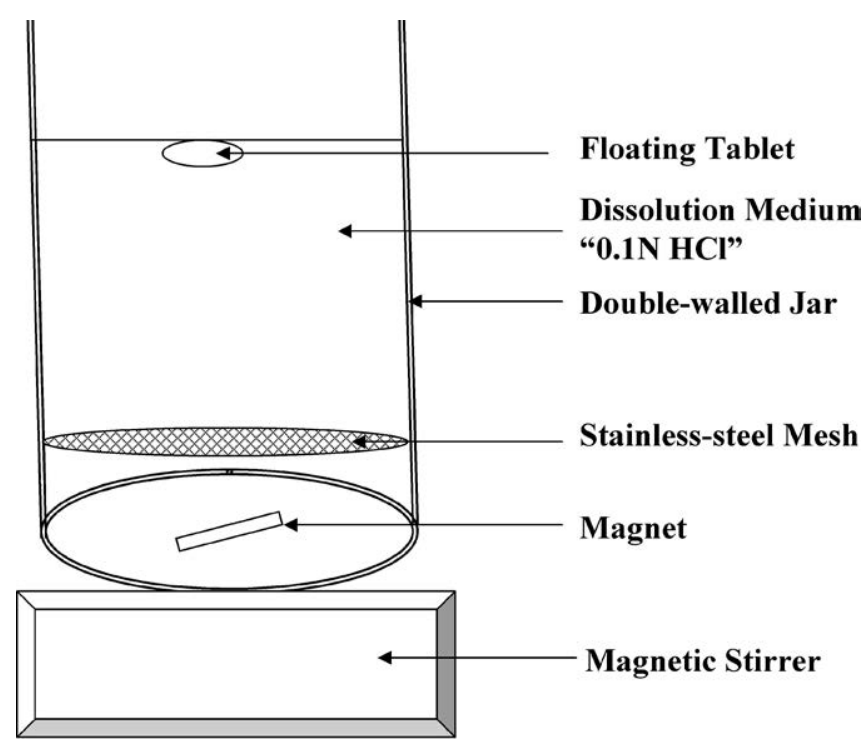

Figure 2. Schematic diagram showing the position of an AmoxT floating tablet in the beaker method.
Stability of AmoxT in Acidic Solution at $\mathrm{pH} 1.2$

AmoxT was reported to be rather unstable in aqueous solution, and the half-life of amoxicillin in acidic solution at $\mathrm{pH} 1$ was $5.2 \mathrm{~h}(32,46)$. The stability of AmoxT $(100 \mu \mathrm{g} /$ $\mathrm{mL}$ ) in standard acidic solution at $\mathrm{pH} 1.2$ was determined by measuring the absorbance at $272 \mathrm{~nm}$ after $0,2,4,6$, and $24 \mathrm{~h}$ at $25^{\circ} \mathrm{C}$ and $37^{\circ} \mathrm{C}$. The stability of AmoxT $(10 \mu \mathrm{g} / \mathrm{mL})$ in standard acidic solution at $\mathrm{pH} 1.2$ was determined by the stability indicating HPLC method after $0,2,4$, and $6 \mathrm{~h}$ at $25^{\circ} \mathrm{C}$ and $37^{\circ} \mathrm{C}$. The stability studies were preformed in triplicate.

\section{RESULTS AND DISCUSSION}

In the design of gastric floating drug delivery systems, the two mechanisms most frequently used are low-density tablet ingredients and gas-generating agents (47). A lowdensity drug delivery system can be achieved by using PEO, HPMC, or both in a polymeric delivery system. Upon contact with water, a hydrogel layer will be formed to act as a gel boundary for the delivery system. The other mechanism of floatation, gas generation, was also incorporated into these tablets. This was achieved by incorporating sodium bicarbonate and calcium carbonate into the delivery system. When water penetrates the tablet, generation of carbon dioxide occurs, which becomes trapped in the polymeric system and helps the floatation of the delivery system (47).

The average values of floating lag time and floating duration of the prepared tablets were $15.0 \mathrm{~min}$ and more than $6 \mathrm{~h}$, respectively. It was interesting to note that the tablets floated in less than $30 \mathrm{sec}$ in the dissolution cell of the FTC apparatus during the in vitro dissolution study (dynamic test) (Figure 3), compared with the beaker method (static test) (Figure 4). This observation has been also pointed out by Jiménez-Castellanos et al. (44) where sotalol $\mathrm{HCl}$ tablets floated after $27.7 \mathrm{~min}$ in the beaker method under static conditions and after 10.3 min during the dissolution test using USP basket method.

The modified HPLC method of Erah et al. (46) used to monitor the intact AmoxT was linear over the concentration range of $2.0-30.0 \mu \mathrm{g} / \mathrm{mL}$. The regression coefficient $R^{2}$, slope, and intercept of the constructed calibration curve were $0.9989,4.91 \times 10^{5}$, and $1.37 \times 10^{5}$, respectively. Values of the percentage recovery were found to be $89.99 \%, 101.66 \%, 103.13 \%, 102.82 \%$, and $98.40 \%$ for 2.0, 5.0, 10.0, 20.0, and $30.0 \mu \mathrm{g} / \mathrm{mL}$, respectively. Values of the respective percentage coefficients of variation were $9.51,5.02,4.80,7.28$, and 4.30 . These data proved that the adopted method was sensitive, accurate, and precise. Figure 5 shows that the method was selective and separated intact AmoxT from its degradation product.

The stability of AmoxT in acidic solution was studied at room temperature $\left(25^{\circ} \mathrm{C}\right)$, as an indication of bench and autosampler stability, and at $37^{\circ} \mathrm{C}$ (to mimic dissolution test conditions). It was interesting to investigate the bench stability of samples after at least $2 \mathrm{~h}$, as the time taken to analyze each sample by HPLC method was about 8.0 min (run time in Figure 5). 


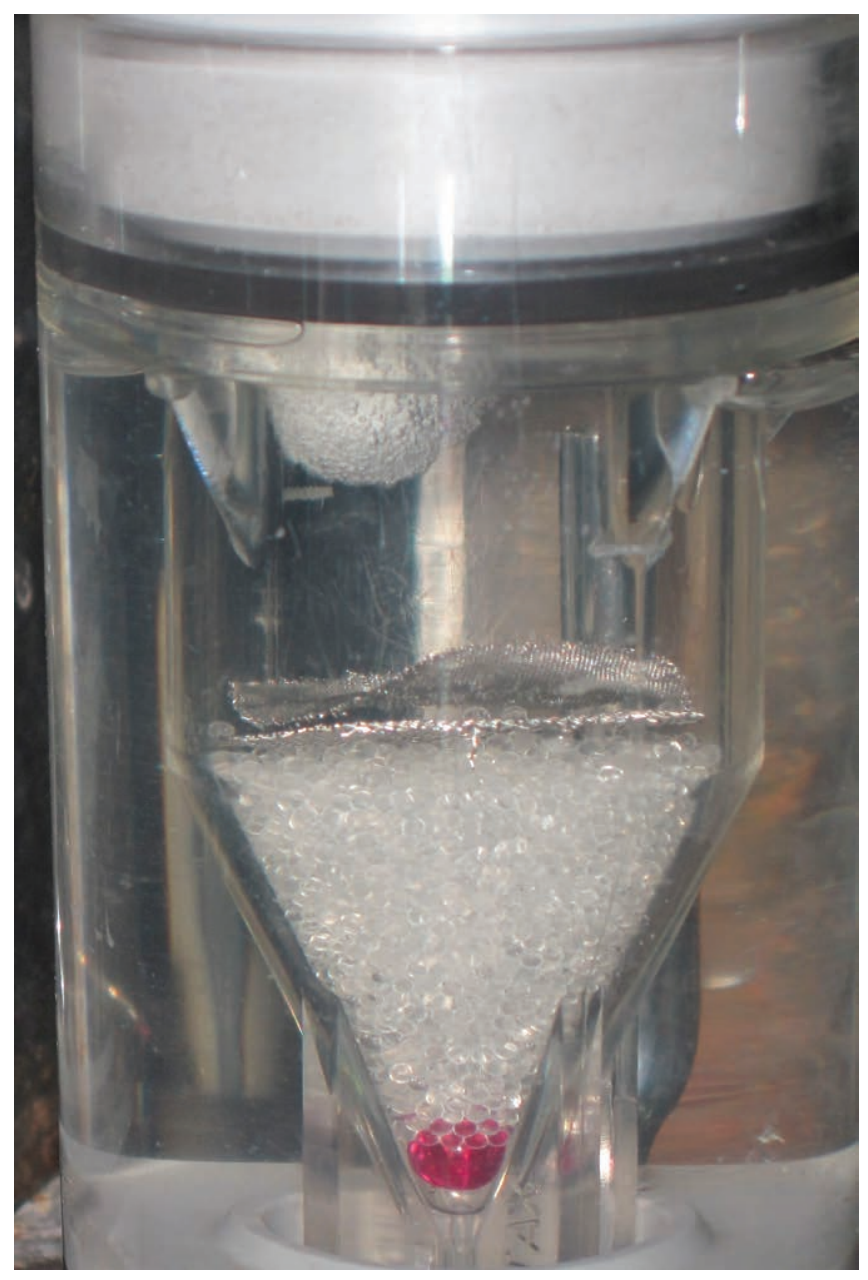

Figure 3. Photograph of an AmoxT floating tablet in the FTC.

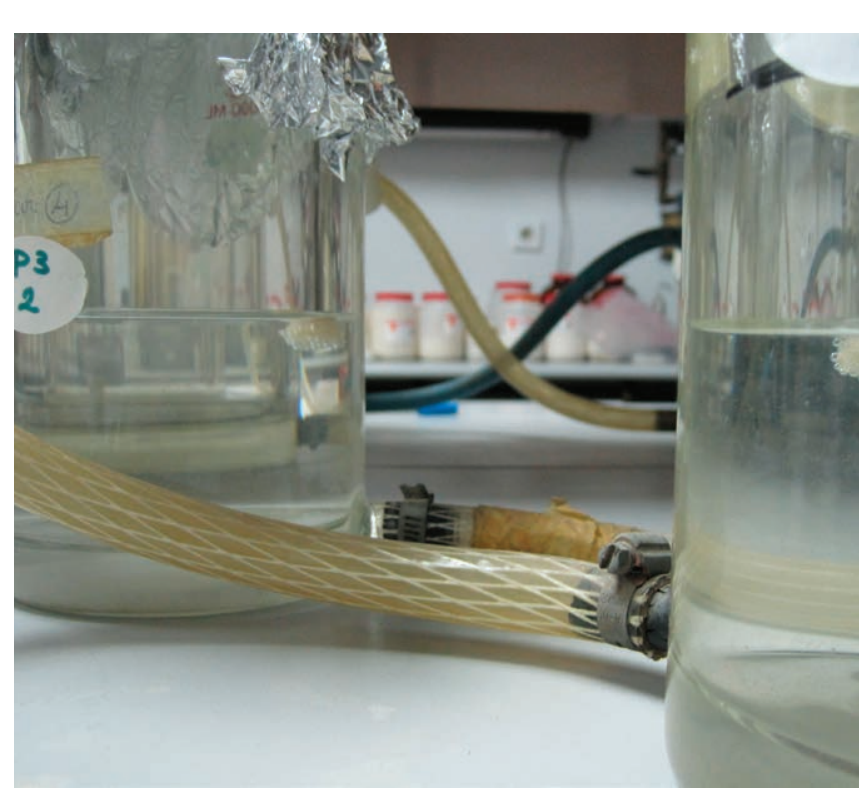

Figure 4. Photograph of an AmoxT floating tablet in the beaker.
Table 1 shows the stability data of AmoxT in acidic solution at $\mathrm{pH} 1.2$, which were determined by HPLC method at two different temperatures, $25^{\circ} \mathrm{C}$ and $37^{\circ} \mathrm{C}$. The HPLC data indicate that AmoxT degraded and the concentration in the solution decreased over time. This result (at $37^{\circ} \mathrm{C}$ ) is in agreement with results of Erah et al. (46) and Tokumura et al. (32). This degradation increased by increasing the temperature from $25^{\circ} \mathrm{C}$ to $37^{\circ} \mathrm{C}$, where after $6 \mathrm{~h}$ the residual percentages of AmoxT were $77.18 \%$ and $67.83 \%$ at $25^{\circ} \mathrm{C}$ and $37^{\circ} \mathrm{C}$, respectively. In this regard, the degradation result at $25^{\circ} \mathrm{C}$ indicates poor autosampler stability.

Table 2 shows the stability data of AmoxT in acidic solution at $\mathrm{pH} 1.2$ from the UV spectrophotometric method after incubation of the standard solutions at $25^{\circ} \mathrm{C}$ and $37^{\circ} \mathrm{C}$. The data obtained from the UV spectrophotometric method show that the concentration of AmoxT apparently increased with time. This phenomenon was brought about by the increase in UV absorption at $272 \mathrm{~nm}$, which was accompanied by the degradation of AmoxT (32) and was more apparent at higher temperatures. This might indicate a direct relationship between AmoxT degradation and temperature (Table 2).

Based on these results, HPLC is not the recommended method of analysis due to autosampler instability of
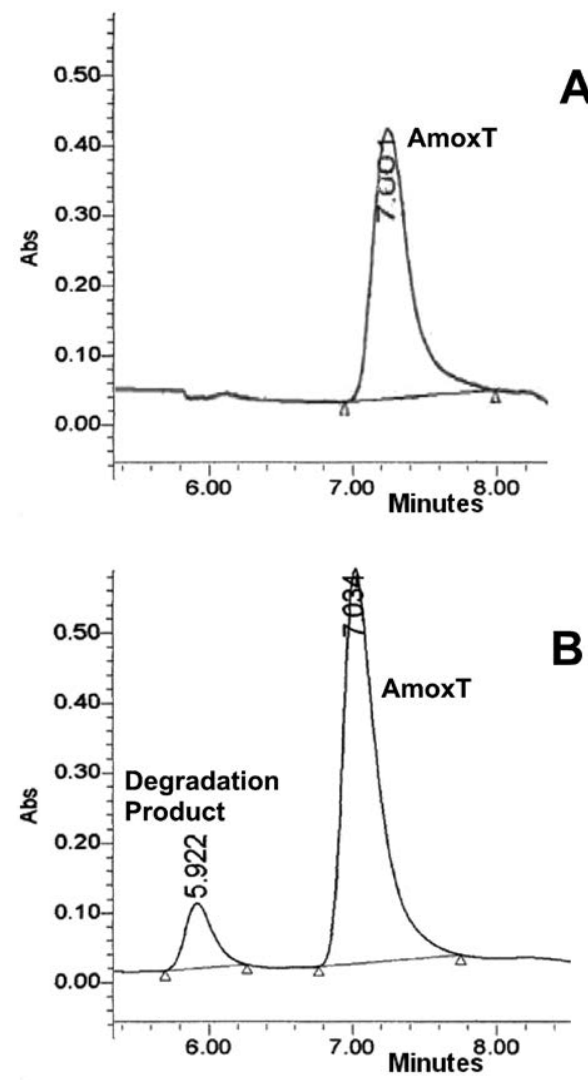

Figure 5. Chromatograms of AmoxT and its degradation product in acidic medium; (A) $2 \mu \mathrm{g} / \mathrm{mL}$ AmoxT spiked in $0.1 \mathrm{~N} \mathrm{HCl}(\mathrm{pH}$ 1.2) and (B) AmoxT and its degradation product. 


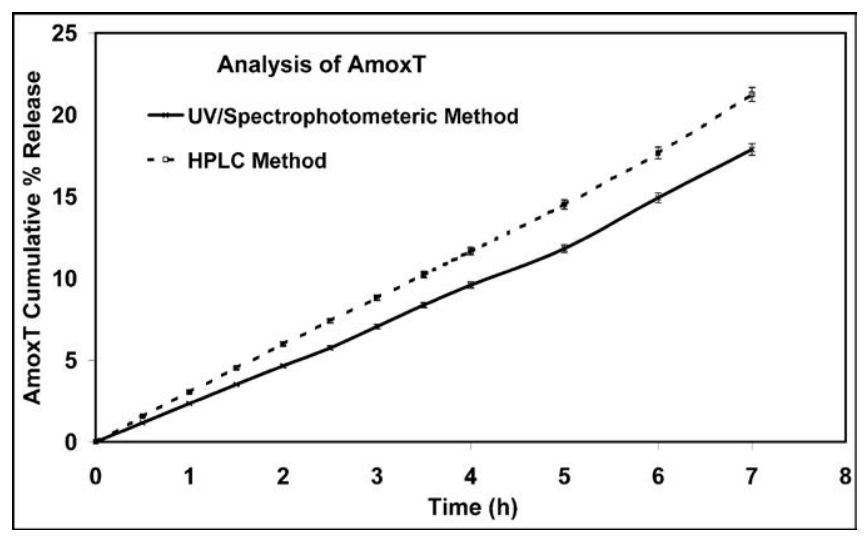

Figure 6. Cumulative percentage release of AmoxT from floating tablets using the open-loop system of the FTC apparatus.

AmoxT, especially when the retention time $\left(R_{t}\right)$ is relatively long (8.0 min, Figure 5). For QC testing of sustained-release products, 12 tablets must be tested simultaneously, which means that the analysis of each fraction (e.g., first fractions collected after $0.5 \mathrm{~h}$ ) will take about $1.6 \mathrm{~h}$. Therefore, an accurate, less time-consuming UV spectrophotometric method might overcome these obstacles.

Figure 6 shows the release rate profiles of AmoxT floating tablets using the open-loop system of the FTC method. The cumulative percentage release of AmoxT was slightly higher when the drug was analyzed by HPLC than by the UV spectrophotometric method. However, this difference between the two methods of analysis was

Table 1. Stability of AmoxT in Acidic Solution at pH 1.2

\begin{tabular}{ccc}
\hline & \multicolumn{2}{c}{ Residual AmoxT (\%) } \\
\cline { 2 - 3 } Time (h) & $\mathbf{2 5}{ }^{\circ} \mathbf{C}$ & $\mathbf{3 7}{ }^{\circ} \mathbf{C}$ \\
\hline $\mathbf{0}$ & $100.00 \pm 0.87$ & $100.00 \pm 0.87$ \\
\hline $\mathbf{2}$ & $89.34 \pm 1.21$ & $85.72 \pm 0.69$ \\
\hline $\mathbf{4}$ & $81.69 \pm 0.89$ & $73.19 \pm 1.30$ \\
\hline $\mathbf{6}$ & $77.18 \pm 0.75$ & $67.83 \pm 0.89$
\end{tabular}

${ }^{a}$ Each value represents the mean $\pm S D(n=3)$. Difference of residual percent between standard solution incubated at $25^{\circ} \mathrm{C}$ and $37^{\circ} \mathrm{C}$ analyzed by HPLC. The initial concentration of AmoxT was $10 \mu \mathrm{g} / \mathrm{mL}$.

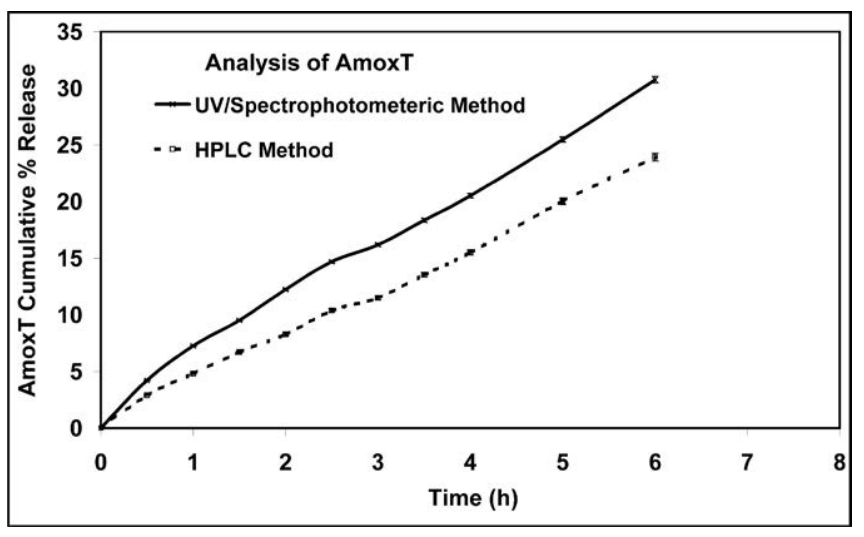

Figure 7. Cumulative percentage release of AmoxT from floating tablets using the beaker method.

not significant (ANOVA test, $p>0.05$ ). The reproducibility of the results was high as detected by the low standard deviation values.

The HPLC method shows negligible degradation of AmoxT in samples collected from the open-loop system of the FTC because the open-loop system of the FTC allowed for the collection and analysis of fresh samples. In this case, the difference between the data of the two methods was simply a matter of accuracy between the HPLC and UV spectrophotometric methods.

On the other hand, for the beaker method (Figure 7), UV spectrophotometric data shows that the concentration of AmoxT increased with time. This phenomenon was brought about by the increase of UV absorption at 272 $\mathrm{nm}$ (32), which was accompanied by accumulation of the degradation product of AmoxT (Figure 5). There was also a significant difference $(p<0.05)$ between the two release rates obtained by the two methods of analysis. This significant difference was a direct result of the inability of the UV method to differentiate between AmoxT and its degradation product. The amounts of AmoxT released in $900 \mathrm{~mL}$ acidic dissolution medium were successively accumulating. In this case, the dissolution samples contained cumulative AmoxT released in the acidic medium rather than fresh samples. Therefore, the release rate data showed a higher AmoxT degradation rate that gave higher UV

Table 2. Stability of AmoxT in Acidic Solution at pH 1.2

\begin{tabular}{cccccc}
\hline & \multicolumn{2}{c}{$\mathbf{2 5}{ }^{\circ} \mathbf{C}$} & & \multicolumn{3}{c}{$\mathbf{3 7}{ }^{\circ} \mathbf{C}$} \\
\cline { 2 - 3 } \cline { 5 - 6 } Time (h) & UV Absorbance & Residual AmoxT (\%) & & UV Absorbance & Residual AmoxT (\%) \\
\hline $\mathbf{0 . 0}$ & $0.314 \pm\left(2.95 \times 10^{-3}\right)$ & $104.7 \pm 0.98$ & $0.314 \pm\left(2.95 \times 10^{-3}\right)$ & $104.7 \pm 0.98$ \\
\hline $\mathbf{2 . 0}$ & $0.336 \pm\left(3.46 \times 10^{-3}\right)$ & $112.0 \pm 1.15$ & $0.367 \pm\left(3.89 \times 10^{-3}\right)$ & $122.3 \pm 1.30$ \\
\hline $\mathbf{4 . 0}$ & $0.360 \pm\left(3.20 \times 10^{-3}\right)$ & $120.0 \pm 1.07$ & $0.381 \pm\left(3.31 \times 10^{-3}\right)$ & $127.0 \pm 1.10$ \\
\hline $\mathbf{6 . 0}$ & $0.379 \pm\left(3.89 \times 10^{-3}\right)$ & $126.3 \pm 1.16$ & $0.388 \pm\left(3.76 \times 10^{-3}\right)$ & $129.3 \pm 1.25$ \\
\hline $\mathbf{2 4 . 0}$ & $0.437 \pm\left(4.28 \times 10^{-3}\right)$ & $145.7 \pm 1.43$ & $0.576 \pm\left(5.93 \times 10^{-3}\right)$ & $192.0 \pm 1.98$ \\
\hline
\end{tabular}

${ }^{a}$ Each value represents the mean $\pm S D(n=3)$. Difference of residual percent between standard solution incubated at $25^{\circ} \mathrm{C}$ and $37^{\circ} \mathrm{C}$ analyzed by $U V$ spectrophotometric method. The initial concentration of AmoxT was $100 \mu \mathrm{g} / \mathrm{mL}$. 
absorbances and hence overestimation of the amounts of AmoxT released.

Therefore, it is required to establish a simple, selective, and sensitive method for analysis as well as specific dissolution conditions to overcome the errors in the release data. This study proposed a simple dissolution method capable of discriminating between different AmoxT gastroretentive formulations without any additional experimental or calculation steps, such as correction for degradation product (18) and the variation of degradation kinetics (33), which allow for additional experimental errors. Furthermore, the UV method could be applied as a simpler and lower cost method than the time-consuming and more expensive HPLC method.

These data demonstrate that the proposed in vitro dissolution study design could be the method for evaluation of gastroretentive AmoxT products and could be applied to other gastroretentive products containing active moieties likely to decompose or degrade in acidic test media.

\section{CONCLUSIONS}

The open-loop system of the FTC apparatus is recommended for the evaluation of gastroretentive AmoxT products in acidic dissolution media. The advantage of this proposed method is that the analysis of AmoxT can be carried out safely with a UV spectrophotometric method, which is considered a simple and economic method of analysis. Furthermore, due to the autosampler instability of AmoxT in acidic medium, HPLC might not be a suitable method of analysis applied for determining AmoxT in acidic media.

USP paddle and basket methods are not the proper methods for evaluation of AmoxT gastroretentive products. Based on the results of this study, the use of the open-loop system of the FTC could be applied to other floating dosage forms containing an active ingredient that is unstable in acidic test media.

\section{REFERENCES}

1. Pandit, V.; Suresh, S.; Joshi, H. Peptic ulcer and its management. J. Pharm. Res. 2008, 1 (2), 245-252.

2. Snowden, F. M. Emerging and reemerging diseases: a historical perspective. Immunol. Rev. 2008, 225 (1), 9-26.

3. Ateshkadi, A.; Lam, N. P.; Johnson, C. A. Helicobacter pylori and peptic ulcer disease. Clin. Pharm. 1993, 12 (1), 34-48.

4. Murray, D. M. Clinical relevance of infection by Helicobacter pylori. Clin. Microbiol. Newsl. 1993, 15 (5), 33-37.

5. Hunt, R. H. Helicobacter pylori Eradication: A Critical Appraisal and Current Concerns. Scand. J. Gastroentero. 1995, 30 (S210), 73-76.

6. Shah, S.; Qaqish, R.; Patel, V.; Amiji, M. Evaluation of the factors influencing stomach-specific delivery of antibacterial agents for Helicobacter pylori infection. J. Pharm. Pharmacol. 1999, 51 (6), 667-672.
7. Arora, S.; Ali, J.; Ahuja, A.; Khar, R. K.; Baboota, S. Floating Drug Delivery Systems: A Review. AAPS PharmSciTech 2005, 6 (3), E372-E390.

8. Washington, N.; Washington, C.; Wilson, C. G. Physiological Pharmaceutics: Barriers to Drug Absorption, 2nd ed.; Taylor and Francis Inc.: New York, 2001.

9. Vijayakumar, A.; Senthilnathan. B.; Ravichandiran, V. A review article on different types of floating drug delivery systems. Int. J. Pharm. Pharm. Sci. 2012, 4 (1), 45-50.

10. Timmermans, J.; Andre, J. M. Factors controlling the buoyancy and gastric retention capabilities of floating matrix capsules: new data for reconsidering the controversy. J. Pharm. Sci. 1994, 83, 18-24.

11. Sahu, A. K.; Verma, A.; Singh, S. K. Preparation of hydrophilic swelling controlled-release floating matrix tablets containing HPMC and chitosan. Int. J. Pharm. Pharm. Sci. 2012, 4 (1), 406-411.

12. Bardonnet, P. L.; Faivre, V.; Pugh, W. J.; Piffaretti, J. C.; Falson, F. Gastroretentive dosage forms: Overview and special case of Helicobacter pylori. J. Control. Release 2006, $111(1-2), 1-18$.

13. Nayak, A. K.; Maji, R.; Das, B. Gastroretentive drug delivery systems: a review. Asian J. Pharm. Clin. Res. 2010, 3 (1), 2-10.

14. Sabale, V.; Sakarkar, S. N.; Pund, S.; Sabale, P. M. Formulation and evaluation of floating dosage forms: An overview. Syst. Rev. Pharm. 2010, 1 (1), 33-39.

15. Martindale, the Complete Drug Reference, $34^{\text {th }}$ ed.; Sweetman, S. C., Ed.; Pharmaceutical Press: London, 2005.

16. Cuña, M.; Alonso, M. J.; Torres, D. Preparation and in vivo evaluation of mucoadhesive microparticles containing amoxicillin-resin complexes for drug delivery to the gastric mucosa. Eur. J. Pharm. Biopharm. 2001, 51 (3), 199-205.

17. Risbud, M. B.; Hardikar, A. A.; Bhat, S. V.; Bhonde, R. R. $\mathrm{pH}$ sensitive freeze-dried chitosan-polyvinyl pyrrolidone hydrogels as controlled release system for antibiotic delivery. J. Control. Release 2000, 68 (1), 23-30.

18. Tapia-Albarran, M.; Villafuerte-Robles, L. Assay of amoxicillin sustained release from matrix tablets containing different proportions of Carbopol 971P NF. Int. J. Pharm. 2004, 273 (1-2), 121-127.

19. Badhan, A. C.; Mashru, R. C.; Shah, P. P.; Thakkar, A. R.; Dobaria, N. B. Development and Evaluation of Sustained Release Gastroretentive Minimatrices for Effective Treatment of H. pylori Infection. AAPS PharmSciTech 2009, 10 (2), 459-467.

20. Hoffman, A.; Danenberg, H. D.; Katzhendler, l.; Shuval, R.; Gilhar, D.; Friedman, M. Pharmacodynamic and pharmacokinetic rationales for the development of an oral controlled-release amoxicillin dosage form. J. Control. Release 1998, 54 (1), 29-37.

21. Craig, W. A.; Ebert, S. C. Killing and regrowth of bacteria in vitro: A review. Scand. J. Infect. Dis. Suppl. 1991, 74, 63-70. 
22. Drusano, G. L. Role of Pharmacokinetics in the Outcome of Infections. Antimicrob. Agents Chemother. 1988, 32 (3), 289-297.

23. Vogelman, B.; Gudmundsson, S.; Leggett, J.; Turnidge, J.; Ebert, S.; Craig, W. A. Correlation of Antimicrobial Pharmacokinetic Parameters with Therapeutic Efficacy in an Animal Model. J. Infect. Dis. 1988, 158 (4), 831-847.

24. Craig, W. A.; Ebert, S. C. Continuous infusion of betalactam antibiotics. Antimicrob. Agents Chemother. 1992, 36 (12), 2577-2583.

25. Weitschies, W.; Friedrich, C.; Wedemeyer, R. S.; Schmidtmann, M.; Kosch, O.; Kinzig, M.; Trahms, L.; Sörgel, F.; Siegmund, W.; Horkovics-Kovats, S.; Schwarz, F.; Raneburger, J.; Mönnikes, H. Bioavailability of amoxicillin and clavulanic acid from extended release tablets depends on intragastric tablet deposition and gastric emptying. Eur. J. Pharm. Biopharm. 2008, 70 (2), 641-648.

26. Karande, A. D.; Yeole, P. G. Comparative Assessment of Different Dissolution Apparatus for Floating Drug Delivery Systems. Dissolution Technol. 2006, 13 (1), 20-23.

27. Dürig, T.; Fassihi, R. Evaluation of floating and sticking extended release delivery systems: an unconventional dissolution test. J. Control. Release 2000, 67 (1), 37-44.

28. Burns, S. J.; Attwood, D.; Barnwell, S. G. Assessment of a dissolution vessel designed for use with floating and erodible dosage forms. Int. J. Pharm.1998, 160 (2), 213-218.

29. Parikh, R. K.; Parikh, D. C.; Delvadia, R. R.; Patel, S. M. A Novel Multicompartment Dissolution Apparatus for Evaluation of Floating Dosage Form Containing Poorly Soluble Weakly Basic Drug. Dissolution Technol. 2006, 13 (1), 14-19.

30. Gohel, M. C.; Mehta, P. R.; Dave, R. K.; Bariya, N. H. A More Relevant Dissolution Method for Evaluation of Floating Drug Delivery System. Dissolution Technol. 2004, 11 (4), 22-25.

31. Özdemir, N.; Ordu, S.; Özkan, Y. Studies of Floating Dosage Forms of Furosemide: In Vitro and In Vivo Evaluations of Bilayer Tablet Formulations. Drug Dev. Ind. Pharm. 2000, 26 (8), 857-866.

32. Tokumura, T.; Machida, Y. UV absorption method should not be applied for determining amoxycillin in acidic dissolution test medium. Int. J. Pharm. 2001, 228 (1-2), 1-4.

33. Umamaheshwari, R. B.; Ramteke, S.; Jain, N. K. AntiHelicobacter pylori effect of mucoadhesive nanoparticles bearing amoxicillin in experimental gerbils model. AAPS PharmSciTech 2004, 5 (2), 60-68.

34. Prabhu, N. B.; Marathe, A. S.; Jain, S.; Singh, P. P.; Sawant, K.; Rao, L.; Amin, P. D. Comparison of Dissolution Profiles for Sustained Release Resinates of BCS Class I Drugs Using USP Apparatus 2 and 4:
A Technical Note. AAPS PharmSciTech 2008, 9 (3), 769-773.

35. Singh, I.; Aboul-Enein, H. Y. Advantages of USP Apparatus IV (flow-through cell apparatus) in dissolution studies. J. Iran. Chem. Soc. 2006, 3 (3), 220-222.

36. Atyabi, F.; Koochak, M.; Dinarvand, R. The effect of loading solution and dissolution media on release of Diclofenac from ion exchange resins. DARU 2002, 10 (1), 17-22.

37. Emara, L. H.; Taha, N. F.; Mursi, N. M. Investigation of the Effect of Different Flow-Through Cell Designs on the Release of Diclofenac Sodium SR Tablets. Dissolution Technol. 2009, 16 (2), 23-31.

38. Banaker, U. V. Pharmaceutical Dissolution Testing; Drugs and the Pharmaceutical Sciences, Vol. 49; Marcel Dekker, Inc.: New York, 1992.

39. Bhattachar, S. N.; Wesley, J. A.; Fioritto, A.; Martin, P. J.; Babu, S. R. Dissolution testing of a poorly soluble compound using the flow-through cell dissolution apparatus. Int. J. Pharm. 2002, 236 (1-2), 135-143.

40. Nicolaides, E.; Symillides, M.; Dressman, J. B.; Reppas, C. Biorelevant Dissolution Testing to Predict the Plasma Profile of Lipophilic Drugs After Oral Administration. Pharm. Res. 2001, 18 (3) 380-388.

41. Butler, W. C. G.; Bateman, S. R. A flow-through dissolution method for a two component drug formulation where the actives have markedly differing solubility properties. Int. J. Pharm. 1998, 173 (1-2), 211-219.

42. Fotaki, N. Flow-Through Cell Apparatus (USP Apparatus 4): Operation and Features. Dissolution Technol. 2011, 18 (4), 46-49.

43. Emara, L. H.; Abdou, A. R.; El-Ashmawy, A. A.; Badr, R. M.; Mursi, N. M. In vitro evaluation of floating matrix tablets of amoxicillin and metronidazole for the eradication of helicobacter pylori. Int. J. Pharm. Pharm. Sci. 2012, 4 (3), 671-681.

44. Jiménez-Castellanos, M. R.; Zia, H.; Rhodes, C. T. Design and testing in vitro of a bioadhesive and floating drug delivery system for oral application. Int. J. Pharm. 1994, 105 (1), 65-70.

45. Tadros, M. I. Controlled-release effervescent floating matrix tablets of ciprofloxacin hydrochloride: development, optimization and in vitro-in vivo evaluation in healthy human volunteers. Eur. J. Pharm. Biopharm. 2010, 74 (2), 332-339.

46. Erah, P. O.; Goddard, A. F.; Barrett, D. A.; Shaw, P. N.; Spiller, R. C. The stability of amoxycillin, clarithromycin and metronidazole in gastric juice: Relevance to the treatment of Helicobacter pylori infection. J. Antimicrob. Chemother. 1997, 39 (1), 5-12.

47. Li, S.; Lin, S.; Chien, Y. W.; Daggy, B. P.; Mirchandani, H. L. Statistical optimization of gastric floating system for oral controlled delivery of calcium. AAPS PharmSciTech 2001, 2 (1), 11-22. 